\title{
Anti-proliferation effect of BMI-1 in U937 cells with siRNA
}

\author{
WEI ZHU, LING HUANG, XUEJING XU, HUI QIAN and WENRONG XU \\ School of Medical Science and Laboratory Medicine, Jiangsu University, \\ 301 Xuefu Road, Zhenjiang, Jiangsu 212013, P.R. China
}

Received February 9, 2010; Accepted April 8, 2010

DOI: 10.3892/ijmm_00000419

\begin{abstract}
Polycomb protein BMI-1 is often overexpressed in various types of leukemia, and its depletion in those leukemic cells leads to cell proliferation arrest, differentiation, and apoptosis. These findings have led us to believe that Bmi-1 has potential as a therapeutic target for leukemia. In this study, we tested multiple sets of synthetic siRNA oligo pairs for downregulating the expression of Bmi-1 in U937 cells, and explored the possible biological effects of BMI-1 suppression on cell growth and proliferation. We found that one siRNA oligo pair can efficiently knock down BMI-1 in U937 cells as evaluated by real-time RT-PCR as well as Western blot analysis. Furthermore, we found that BMI-1 depletion leads to reduced cell growth and proliferation, and increased cell apoptosis. Our proof-of-principle findings confirm that Bmi- 1 siRNA can be used as a therapeutic target of any Bmi-l expressing leukemia and other cancer cells.
\end{abstract}

\section{Introduction}

Bmi-1 is an oncogenic partner of c-Myc, which belongs to the Polycomb group family $(1,2)$. The $B m i-1$ gene is located on chromosome $10 \mathrm{p} 13$, a region involved in chromosomal translocations in infant leukemia (3). Bmi-1 is a transcriptional repressor, the most widely known to target the INK4a/ARF locus, which encodes cell cycle regulators and tumor suppressors p16 ${ }^{\mathrm{INK} 4 \mathrm{a}}$ and $\mathrm{p} 19^{\mathrm{ARF}}$ (mouse homolog of human p14 ${ }^{\mathrm{ARF}}$ ) $(4,5)$. Bmi-1 is important for the maintenance of various types of somatic stem cells due to its dominant expression, and it is important in organogenesis owing to the phenotype of Bmi-1 deficient mice. Downregulation of $16^{\mathrm{INK} 4 \mathrm{a}}$ and $\mathrm{p} 19^{\mathrm{ARF}}$ inhibits cell apoptosis induced by $\mathrm{p} 53$ and $\mathrm{pRb}$. Therefore, overexpressed Bmi-1 could result in cell immortalization and tumorigenesis $(6,7)$. Bmi-1 is also essential for leukemic stem cells and perhaps other type of cancer stem cells. It is overexpressed in both hematological malignancies (8-10) and solid

Correspondence to: Dr Wenrong Xu, School of Medical Science and Laboratory Medicine, Jiangsu University, 301 Xuefu Road, Zhenjiang, Jiangsu 212013, P.R. China

E-mail: icls@ujs.edu.cn

Key words: Bmi-1, leukemia, siRNA, U937 cell line, therapeutic target tumors such as non-small cell lung cancer (11), liver (12), breast (13), bladder cancer (14), prostate carcinomas (15) and Ewing sarcoma (16). Therefore, BMI- 1 plays an important role in regulating the proliferation of both normal and leukemia stem cells, which is useful as a novel molecular marker to predict the progression and prognosis, and may become clinically useful as a noninvasive diagnostic marker (17-21). Lessard and Sauvageau (6) demonstrated that the proliferative potential of acute myeloid leukemia (AML) stem and progenitor cells lacking Bmi-1 was compromised because they eventually underwent proliferation arrest and showed signs of differentiation and apoptosis. In addition, the absence of Bmi-1 led to transplant failure of the leukemia, and these proliferative defects could be completely rescued by Bmi- 1 . These findings suggest that the Bmi-1 gene is a potential target for therapeutic intervention in leukemia. siRNA has become a novel therapeutic tool acting in the overexpression of genes. In the present study, we investigated the efficacy of siRNA-mediated silencing of Bmi-1 on U937 cell proliferation and apoptosis.

\section{Materials and methods}

Cell culture. The U937 (human leukemic monocyte lymphoma cell line) was maintained in complete DMEM (low glucose, Gibco) medium containing 10\% fetal bovine serum (FBS, Gibco), penicillin $(100 \mathrm{U} / \mathrm{ml})$ and streptomycin $(100 \mu \mathrm{g} / \mathrm{ml})$. Cells were incubated at $37^{\circ} \mathrm{C}$ in humid air with $5 \% \mathrm{CO}_{2}$.

siRNA sequence designs. Three siRNA sequences targeting Bmi-1 were designed and synthesized by Guangzhou Ribobio Co., Ltd., China (Table I).

In vitro transfection with siRNA. U937 cells were transfected with siRNAs according to the manufacturer's instructions (Invitrogen, USA). Briefly, U937 cells were seeded without antibiotics at $1 \times 10^{6}$ cells in a $10-\mathrm{cm}$ tissue culture dish (Nunclon, Denmark). One hour before transfection, cells were refreshed with serum-free medium, and then transfected. Cells were divided into three groups: transfected with Bmi-1specific siRNA as test group (U937B), transfected with nonspecific siRNA (U937N) as a negative control and adding Lipofectamine 2000 (U937L) alone as a control. Cells were transfected with siRNA at a concentration of $50 \mathrm{nM}$. Cells were incubated with siRNA plus Lipofectamine 2000 for $6 \mathrm{~h}$ in transfection medium. Cells were harvested for further studies $72 \mathrm{~h}$ after the beginning of transfection.

To evaluate the efficiency of transfection, FAM-siRNA (Guangzhou Ribobio Co., Ltd, China) was used. After 16 h 
Table I. siRNA sequences targeting Bmi-1.

\begin{tabular}{|c|c|c|}
\hline Gene & Target mRNA (5'-3') & siRNA Duplex \\
\hline GAPDH (human) & ATTCCATGGCACCGTCAAG & $\begin{array}{l}\text { Sense: AUUCCAUGGCACCGUCAAG dTdT } \\
\text { Antisense: dTdT UAAGGUACCGUGGCAGUUC }\end{array}$ \\
\hline Negative (control) & TTCTCCGAACGTGTCACGT & $\begin{array}{l}\text { Sense: UUCUCCGAACGUGUCACGU dTdT } \\
\text { Antisense: dTdT AAGAGGCUUGCACAGUGCA }\end{array}$ \\
\hline siBmi-1 001 & CCAATGGCTCTAATGAAGA & $\begin{array}{l}\text { Sense: CCAAUGGCUCUAAUGAAGAdTdT } \\
\text { Antisense: dTdT GGUUACCGAGAUUACUUCU }\end{array}$ \\
\hline siBmi-1 002 & AAATGGACATACCTAATAC & $\begin{array}{l}\text { Sense: AAAUGGACAUACCUAAUACd TdT } \\
\text { Antisense: dTdT UUUACCUGUAUGGAUUAUG }\end{array}$ \\
\hline siBmi-1 003 & AAATACAGAGTTCGACCTA & $\begin{array}{l}\text { Sense: AAAUACAGAGUUCGACCUA dTdT } \\
\text { Antisense: dTdT UUUAUGUCUCAAGCUGGAU }\end{array}$ \\
\hline
\end{tabular}

transfection, the number of FAM-labeled cells was estimated with flow cytometry analysis.

Real-time quantitative RT-PCR. Total RNA was isolated using Trizol reagent (Invitrogen, USA), and reverse transcription of total RNA was carried out using MMLV-RT, SPCL (Invitrogen, USA). A real-time quantitative PCR was performed by using SYBR Green I. Reaction mixture consisted of $2.5 \mu 1$ 10x PCR buffer, $2.0 \mu \mathrm{l}$ of $2.5 \mathrm{mM}$ of each dNTP, $2.0 \mu 125 \mathrm{mM} \mathrm{MgCl}_{2}$, $0.5 \mu 110 \mathrm{pmol} / \mu 1$ each of primer (GAPDH and Bmi-1), $0.2 \mu 1$ $5 \mathrm{U} / \mu 1 \mathrm{Taq}$ polymerase, $0.5 \mu 1 \mathrm{cDNA}$ template and distilled water for a total volume of $25 \mu \mathrm{l}$. PCR primer sequences were as follows, human GAPDH, forward 5'-CCACCCATG GCAAATTCCATGGCA-3' and reverse 5'-TCTAGACGGC AGGTCAGGTCCAC-3'; Bmi-1, forward 5'-CTTCATTGAT GCCACAACCATA-3' and reverse 5'-TCATTCACCTCCTC CTTAGATT-3'. The thermal cycle conditions were, $94^{\circ} \mathrm{C}$ for $5 \mathrm{~min}, 35$ cycles of $94^{\circ} \mathrm{C}$ for $30 \mathrm{sec}, 56^{\circ} \mathrm{C}(\mathrm{GAPDH}) / 59^{\circ} \mathrm{C}$ (Bmi-1) for $30 \mathrm{sec}$, and $72^{\circ} \mathrm{C}$ for $60 \mathrm{sec}$ and a final extension at $72^{\circ} \mathrm{C}$ for $10 \mathrm{~min}$. Triplicate was made for each sample, and all reactions were repeated three times independently to ensure the reproducibility of the results. The data were then viewed and analyzed using the Rotor-Gene Real-Time Analysis Software (Corbett Rotor-Gene 6000, Australia). For each sample, amplification plot and corresponding dissociation curves were examined. To obtain standardized quantitative results, external controls were constructed consisting of cDNA plasmid standards.

Western blotting. U937 cells were collected by centrifugation for protein extraction using RIPA lyses buffer and protease inhibitor PMSF (Shanghai Shen Neng Bo Cai Co.). Extracted total cellular protein was analyzed by Western blotting. Blotted nitrocellulose film was incubated with mouse-anti BMI-1 IgG antibody (Zymed ${ }^{\circledR}$ Laboratories Inc.) and then peroxidase conjugated goat anti-mouse secondary antibody $(1: 5,000)$ was added. Results of the blotting were visualized via chemiluminescent detection system (Western blotting luminal reagent, Santa Cruz Biotechnology) and analyzed with GeneSnap/ Gene Tool software from Syngene (Cambridge, UK).

Cell proliferation assay. The U937B, U937N and U937L cells were seeded in 24 -well plates ( $1 \times 10^{4} /$ well). Cell numbers and viability were analyzed daily using the trypan blue exclusion assay for 12 consecutive days.
Cell cycle analysis. Transfected and untransfected U937 cells were washed twice with PBS, incubated with PI (500 $\mu \mathrm{l}$ / $10^{6}$ cells) at room temperature for $30 \mathrm{~min}$, and then analyzed by flow cytometry. Cell cycle profiles were analyzed using Cell Quest software (BD, USA).

Flow cytometric apoptosis assay. Samples were performed according to the manufacturer's protocol (Invitrogen, USA). U937 cells ( $1 \times 10^{5}$ cells) were harvested $72 \mathrm{~h}$ after tansfection, washed with PBS and resuspended in $100 \mu 1$ Annexin-binding buffer. We added $5 \mu 1$ annexinV and $1 \mu 1$ of the $100 \mu \mathrm{g} / \mathrm{ml} \mathrm{PI}$ working solution to each $100 \mu 1$ of cell suspension. Cells at room temperature were incubated in the dark for $15 \mathrm{~min}$. After the incubation period, $400 \mu \mathrm{l}$ of $1 \mathrm{x}$ annexin-binding buffer was added, mixed gently and the samples were kept on ice. Then the percentage of apoptotic cells were analyzed by flow cytometry.

TdT-mediated dUTP-biotin nick end labeling (TUNEL) assay. For the TUNEL procedure, an in situ apoptosis detection kit (Boehringer Mannheim, Germany) was applied following the manufacturer's instructions. Pre-treated with siRNA and untreated cells were plated on sterilized coverslips in 12-well plates and fixed in $4 \%$ formaldehyde for $30 \mathrm{~min}$ at room temperature. Nonspecific reactions were blocked with $3 \% \mathrm{H}_{2} \mathrm{O}_{2}$ for $10 \mathrm{~min}$ at room temperature. Terminal deoxynucleotidyl tranferase (TdT) and biotin-11-dUTP reactions were carried out for $1 \mathrm{~h}$ at $37^{\circ} \mathrm{C}$. Removal of TdT from the procedure provided a negative control. HRP-DAB was used for the TUNEL procedure, and hematoxylin was used as a counter stain. Cell apoptosis was calculated as a ratio of the number of TUNELpositive cells to the total number of U937 cells in each coverslip.

Statistics. All data are expressed as the mean \pm SD. The difference between treated and control cells was analyzed by t-test. P-value $<0.05$ was considered statistically significant.

\section{Results}

Exploration of targeting Bmi-1 through siRNA knockdown in U937 cells. As the Bmi-1 is expressed in various leukemic cells, we hypothesized that targeted knockdown of Bmi-1 intervenes in their growth and survival. To prove this we 

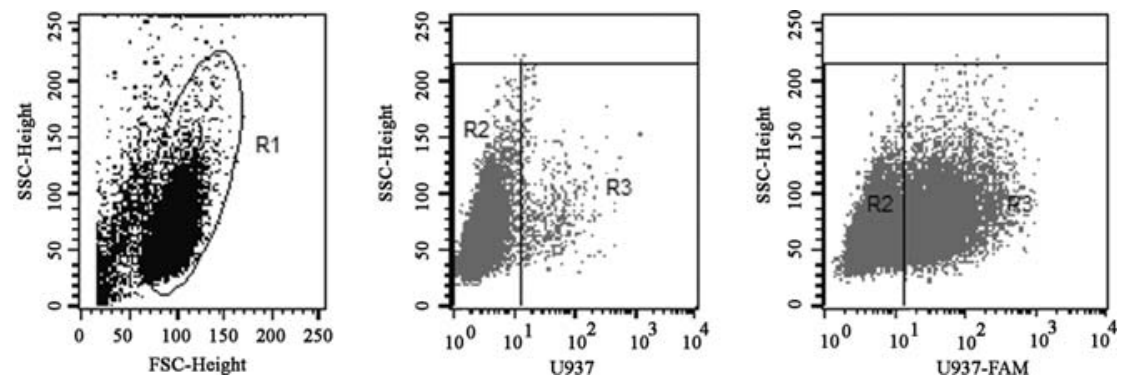

Figure 1. The efficiency of transformation of U937 cells using Lipofectamine 2000. The efficiency of transformation of U937 cells was analyzed by flow cytometry analysis after incubation with FAM-labeled unspecific siRNA over a period of $12 \mathrm{~h}$. The number of transfected cells were increased with incubation time, and the transformation plateaued at $16 \mathrm{~h}$ incubation. At this point the transfection efficiency was $44.91 \%$.

transfected 3 sets of siRNA duplexes into Bmi-1 expressing U937 cells to transiently knock down Bmi-1 using preoptimized Lipofectamine 2000 transfection method since stable knockdown could be detrimental to the cells. The number of transfected cells increased with incubation time. But the transformation plateaued at $16 \mathrm{~h}$ post transfection. At this point the transfection efficiency was $44.91 \%$ (Fig. 1).

To determine the levels of Bmi-1 mRNA after siRNA transfection by RT-PCR and real-time quantitative RT-PCR, three Bmi-1 siRNA targeting the Bmi-1 gene (siBmi-1 001, 002 and 003) and added Lipofectamine 2000 (U937L) alone as a control were tested for silencing in U937 cells, respectively. siBmi-1 001 was determined as the most effective compared to other groups. It induced a remarkable downregulation of Bmi-1 transcript after $72 \mathrm{~h}$ in U937 cells (Fig. 2A). Bmi-1 001 specific siRNA was selected from three pairs for further studies. To further validate the Bmi-1 knockdown at a protein level, Western blot analysis showed that the reduction of mRNA using siRNA-Bmi-1 001 (U937B) resulted in a remarkedly decreased Bmi-1 protein level as compared with non-transfected (U937L) or control-siRNA transfected cells (U937N) considering only the transfection efficiency is $\sim 44 \%$. The protein level was not influenced in U937L and U937N cells compared with non-treated cells (U937) (Fig. 2B).

Effect of Bmi-1 siRNA transfection on the cell cycle. To explore the role of Bmi-1 in cell growth and proliferation in more details, we examined cell cycle profiles of Bmi-1 downregulated cells by flow cytometry (Fig. 3A). The percentage of cells from U937B in the G0/G1 phase increased compared with U937L or U937N cells ( $\mathrm{P}<0.05$, Fig. 3B), and decreased in the $\mathrm{S}$ phase compared with U937L or U937N cells $(\mathrm{P}<0.05$, Fig. 3C). Our data suggest that $\mathrm{Bmi}-1$ is an important player in driving cell proliferative cycles. Since we gate on Bmi-1 siRNA transfected cells in our analysis indicating that those cells are relatively homogeneous.

Cell proliferation in U937 cells transfected with Bmi-1 siRNA. To further detect the effect of downregulation of Bmi-1 on the proliferation of U937 cells, the U937B, U937N and U937L tranfected cells were analyzed for their total cell number counts and viability by the trypan blue exclusion assay every day for 12 consecutive days. The results showed that the total cell number decreased significantly in comparison with U937N and U937L cells, while there was no difference in growth rate between U937L and U937N cells (Fig. 3D). These results

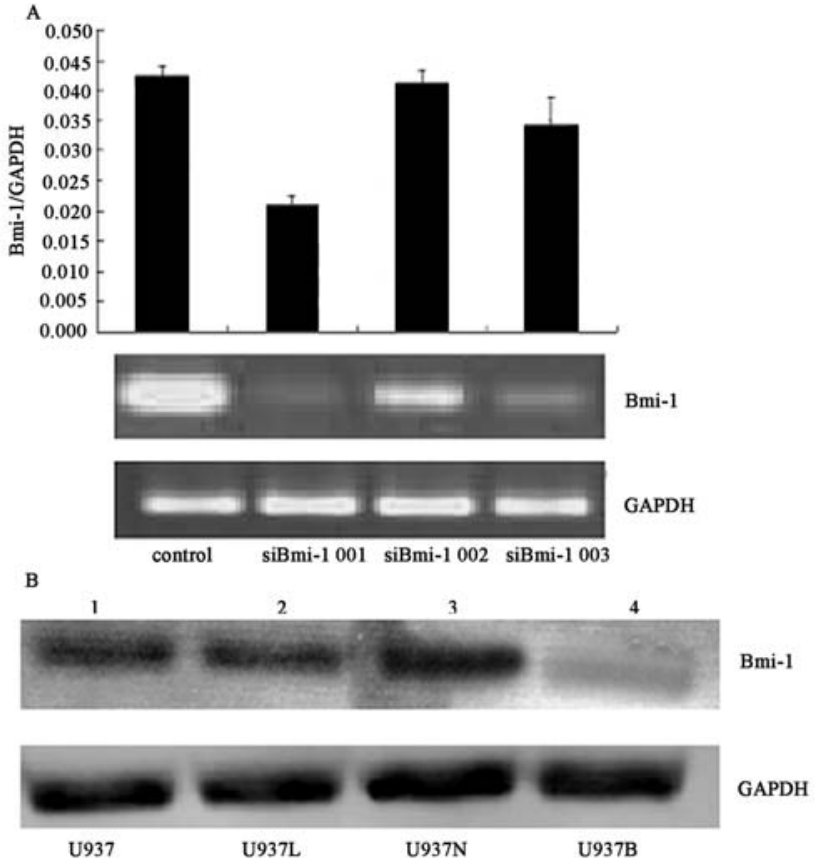

Figure 2. (A) The quantification of Bmi-1 transcript $72 \mathrm{~h}$ after Bmi-1 siRNA transfection. Bmi-1 mRNA experssion in U937 cells treated with siBmi-1 001 , siBmi-1 002, siBmi-1 003 and adding Lipofectamine 2000 alone (U937L) as a control, respestively. Cells were transfected with siRNA at a concentration of $50 \mathrm{nM}$. After $72 \mathrm{~h}$ transfection, Bmi-1 mRNA expression was determined by real-time RT-PCR and RT-PCR with normalization to GAPDH expression. siBmi-1 001 was determined as the most effective compared to other groups. It induced a remarkable downregulation of Bmi-1 transcript after $72 \mathrm{~h}$ in U937 cells. (B) Effect of Bmi-1 siRNA transfection on Bmi-1 protein levels in U937 cells. Lane 1, untreaed U937 cells; 2, U937 cells incubated with Lipofectamine 2000 alone; 3, U937 cells incubated with non-specific Bmi-1 siRNA; 4, U937 cells incubated with siBmi-1 001 specific siRNA.

suggest that BMI-1 is necessary for normal cell growth in U937 cells.

Effect of Bmi-1 siRNA transfection on cell apoptosis. Flow cytometry assay was used to evaluate whether the decrease in cell viability after 24 and $72 \mathrm{~h}$ transfection with Bmi- 1 siRNA resulted from apoptosis (Figs. 4A and 5A). The results show that the percent of annexin $\mathrm{V}$ positive cells after $24 \mathrm{~h}$ of transfection with Bmi-1 001 siRNA increased compared with U937 cells incubated with Lipofectamine 2000 alone or nonspecific Bmi-1 siRNA ( $\mathrm{P}<0.05$, Fig. 4B), but the percent of annexin $\mathrm{V}$ positive cells after $72 \mathrm{~h}$ transfection with Bmi-1 001 

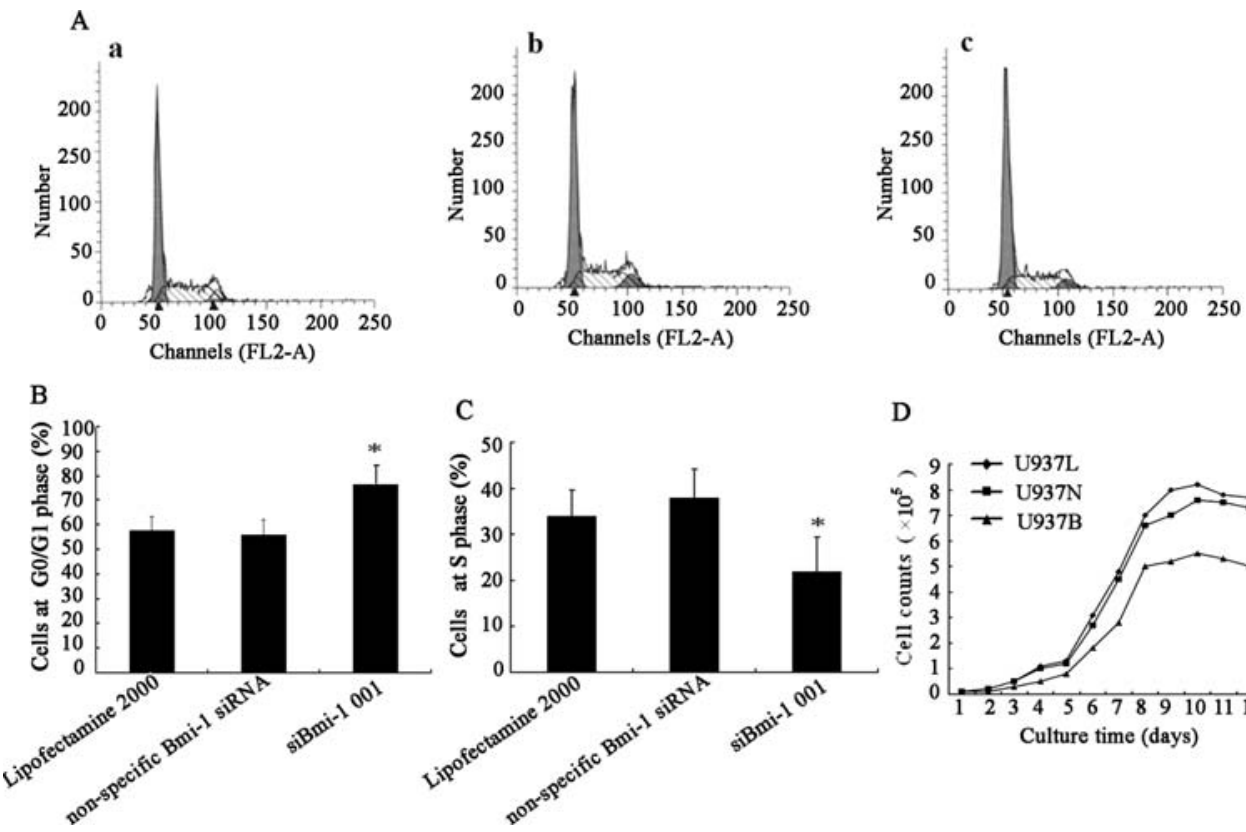

D

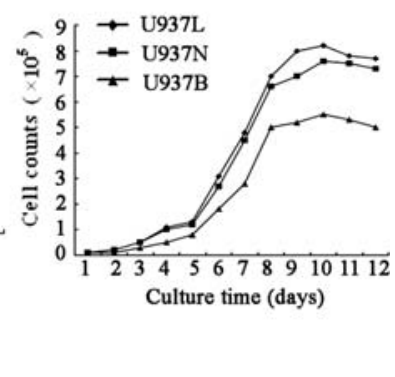

Figure 3. Effects of Bmi-1 siRNA on cell proliferation and cell cycle of U937 cells. (A) DNA content analysis of U937 cells transfected with Bmi-1 001 siRNA (a) U937 cells incubated with Lipofectamine 2000 alone. (b) U937 cells incubated with non-specific Bmi-1 siRNA. (c) U937 cells incubated with siBmi-1 001 specific siRNA. (B) Cells at the G0/G1 phase, the percentage of cells transfected with Bmi-1 001 siRNA in G0/G1 phase increased compared with U937 cells incubated with Lipofectamine 2000 alone or non-specific Bmi-1 siRNA ( $\left.{ }^{*} \mathrm{P}<0.05\right)$. (C) Cells at $\mathrm{S}$ phase, the percentage of cells from transfected with Bmi-1 001 siRNA in G0/G1 phase decreased compared with U937 cells incubated with Lipofectamine 2000 alone or non-specific Bmi-1 siRNA ("P<0.05). Data represent the means \pm SD from triplicate measeurements. (D) Cell proliferation after Bmi-1 silencing. U937 cells treated with Lipofectamine 2000 alone, non-specific Bmi-1 siRNA and siBmi-1 001 specific siRNA, respectively.
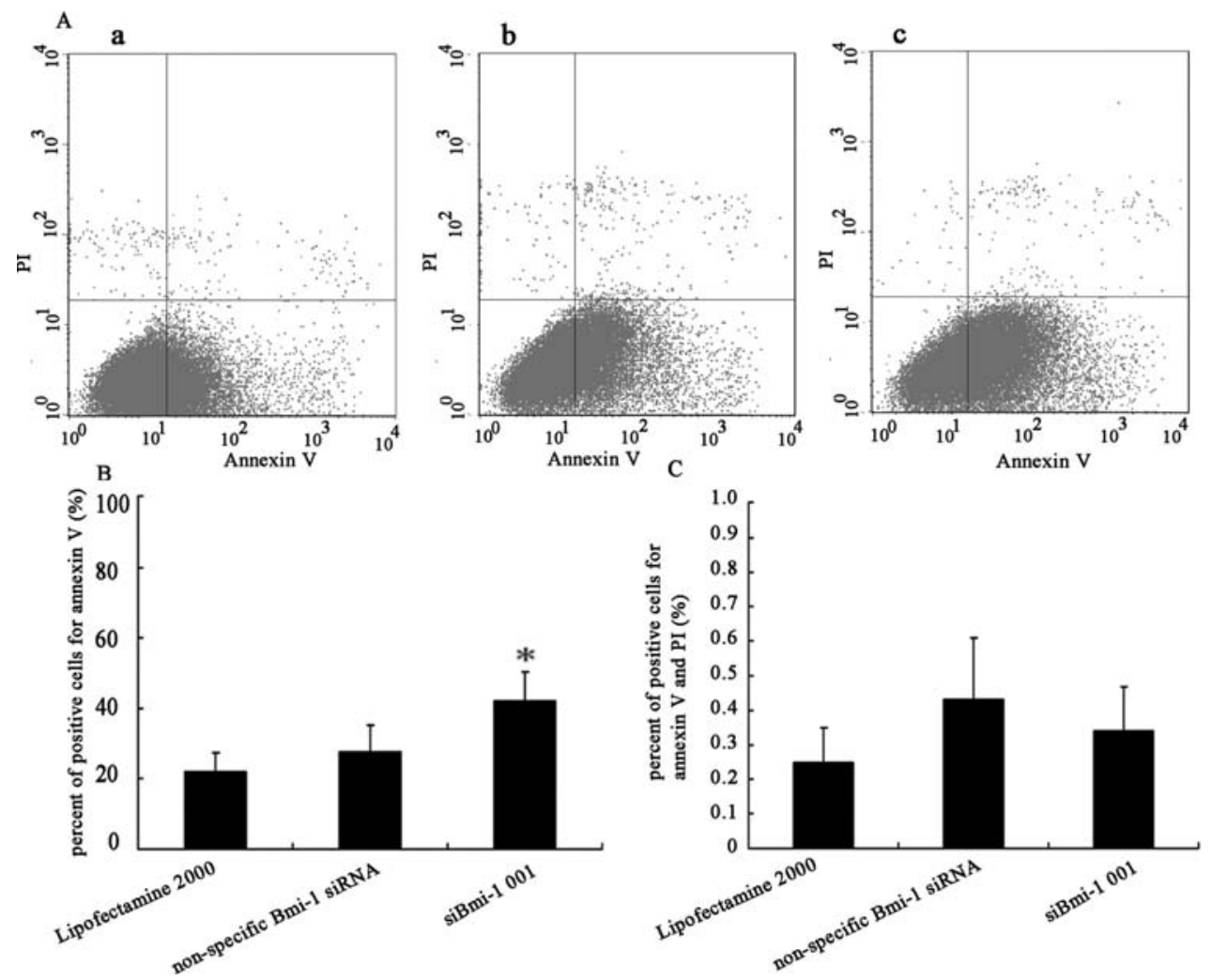

Figure 4. Effect of Bmi-1 siRNA transfection on cell apoptosis by flow cytometric apoptosis assay on cell apoptosis after $24 \mathrm{~h}$ transfection with Bmi-1 001 siRNA. (A) (a-c) U937 cells treated with Lipofectamine 2000 alone, non-specific Bmi-1 siRNA and siBmi-1 001 specific siRNA, respectively. (B) The percent of positive cells for annexin $\mathrm{V}$ were determined in (A), the percent of annexin V positive cells transfected with Bmi-1 001 siRNA increased compared with U937 cells incubated with Lipofectamine 2000 alone or non-specific Bmi-1 siRNA ( $\left.{ }^{*} \mathrm{P}<0.05\right)$. (C) The percent of positive cells for both annexin $\mathrm{V}$ and PI were determined in (A). The percent of both annexin V and PI positive cells transfected with Bmi-1 001 siRNA had no significant difference compared with U937 cells incubated with Lipofectamine 2000 alone or non-specific Bmi-1 siRNA. Data represent the means \pm SD from triplicate measeurements. 


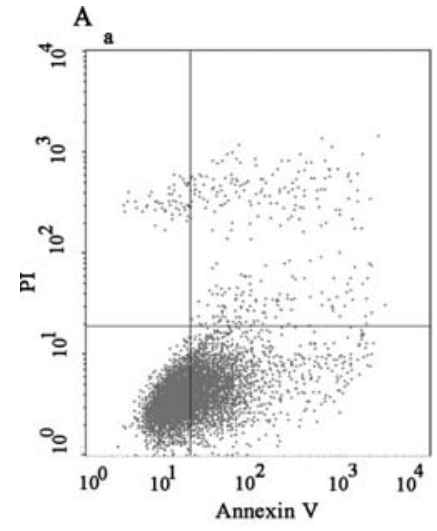

B

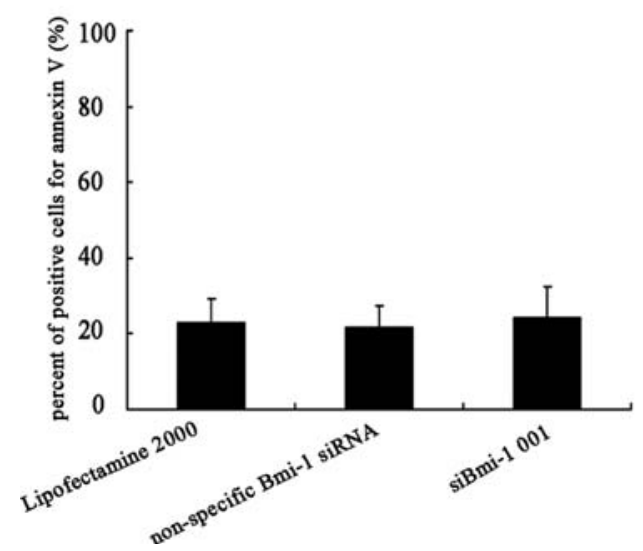

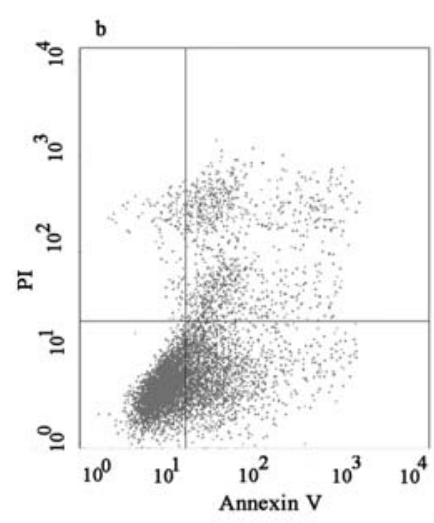

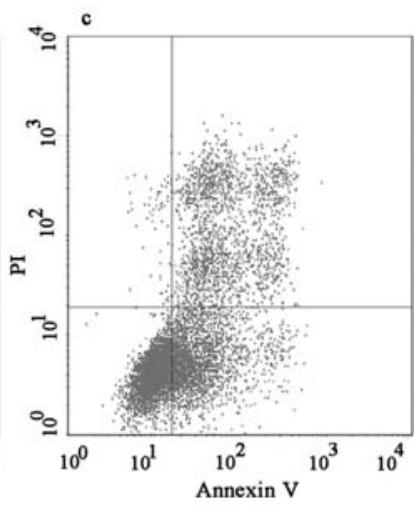

C

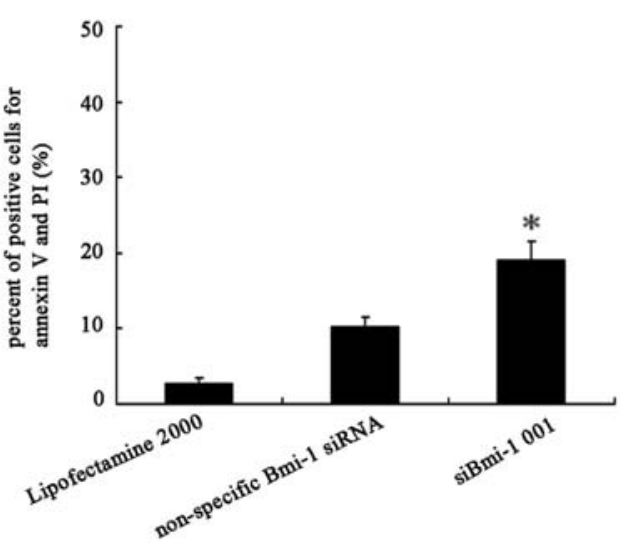

Figure 5. Effect of Bmi-1 siRNA transfection on cell apoptosis by flow cytometric apoptosis assay on cell apoptosis after 72 h transfected with Bmi-1 001 siRNA. (A) (a-c) U937 cells treated with Lipofectamine 2000 alone, non-specific Bmi-1 siRNA and siBmi-1 001 specific siRNA, respectively. (B) The percent of positive cells for annexin $\mathrm{V}$ were determined in (A), the percent of annexin $\mathrm{V}$ positive cells transfected with Bmi-1 001 siRNA had no significant difference compared with U937 cells incubated with Lipofectamine 2000 alone or non-specific Bmi-1 siRNA ( $\left.{ }^{*} \mathrm{P}<0.05\right)$. (C) The percent of positive cells for both annexin V and PI were determined in (A), the percent of both annexin V and PI positive cells transfected with Bmi-1 001 siRNA increased as compared with U937 cells incubated with Lipofectamine 2000 alone or non-specific Bmi-1 siRNA. Data represent the means \pm SD from triplicate measeurements.

siRNA had no significant difference compared with U937 cells incubated with Lipofectamine 2000 alone or non-specific Bmi-1 siRNA (Fig. 5B). While the percent of both annexin V and PI positive cells after $72 \mathrm{~h}$ transfection increased as compared with U937 cells incubated with Lipofectamine 2000 alone or non-specific Bmi-1 siRNA ( ${ }^{*} \mathrm{P}<0.05$, Fig. $\left.5 \mathrm{C}\right)$, the percent of annexin $\mathrm{V}$ and PI positive cells after $24 \mathrm{~h}$ transfection with Bmi-1 001 siRNA had no significant difference compared with U937 cells incubated with Lipofectamine 2000 alone or non-specific Bmi-1 siRNA (Fig. 4C).

TUNEL assay presented similar results as the flow cytometric apoptosis assay, Bmi-1 001 specific siRNA treatment resulted in a significant increase in the percentage of cell apoptosis than that in non-specific Bmi-1 siRNA and adding Lipofectamine 2000 alone (Fig. 6A and B).

\section{Discussion}

BMI-1 is known to play a crucial role in sustaining hematopoietic stem and progenitor cells. It is a potent negative regulator of Ink4a/Arf locus that encodes the cell cycle regulators and tumor suppressors p16Ink4a and p19Arf (p14ARF in humans), a cyclin-dependent kinase inhibitor that regulates cellular senescence. Regarding the cell cycle, BMI-1-positive cells proliferate more rapidly $(6,22)$. BMI-1 may be useful as a molecular marker for the progression of
CML and could be a promising new target for therapeutic treatment of several types of leukemia $(6,18,23,24)$. Yang et al (18) demonstrates that transcription from the Bmi-1 promoter is significantly activated by SALL4 in a dosedependent manner and SALL4 binds to a specific region of the Bmi-1 promoter. These findings suggest a novel link between SALL4 and Bmi-1 in regulating self-renewal of normal and leukemic stem cells.

Due to overexpression of Bmi-1 in U937 cells, we selected it as the test cell line. In this study, Bmi-1 in U937 cells was downreguled with siRNA. Real-time RT-PCR quantification showed a downregulation of Bmi-1 mRNA in U937 cell up to $49 \%$ with siBmi-1 001 transfection, and the reduction of mRNA resulted in a marked decrease of Bmi-1 protein level compared with non-transfected (U937L) or control-siRNA transfected cells (U937N). Cell proliferation assay in U937 cells transfected with Bmi-1 siRNA also indicated that the cell growth of U937 cells decreased significantly in comparison with control cells. Cell cycle analysis showed that the percentage of cells in the G1 phase was increased and that in the $\mathrm{S}$ phase it was decreased significantly in siBmi-1 001 transfected U937 cells. The results indicate that inhibition of U937 cell proliferation by BMI-1 siRNA is mediated by upregulation of p16 which arrested the cell at $\mathrm{G} 1$ to $\mathrm{S}$ phase in its cell cycle $(25,26)$. p16Ink4a is a downstream target of Bmi-1 $(4,14)$, and in the absence of Bmi-1 the cyclin-dependent kinase 

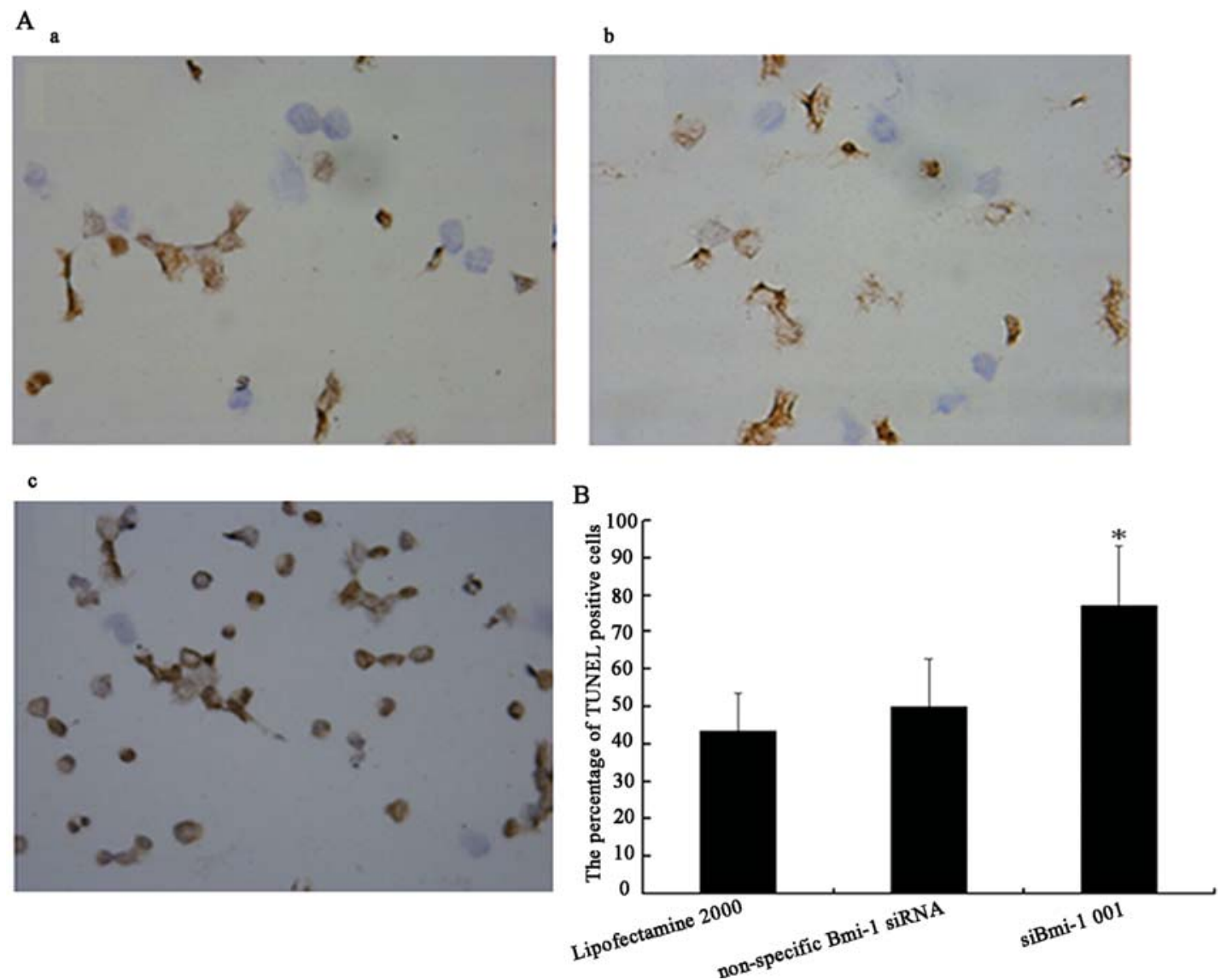

Figure 6. Cell apoptosis detected by TUNEL assay. (A) (a-c) U937 cells treated with Lipofectamine 2000 alone, non-specific Bmi-1 siRNA and siBmi-1 001 specific siRNA, respectively. (B) The cell apoptosis was calculated as a ratio of the number of TUNEL-positive cells to the total number of U937 cells in each coverslip. The ratio of TUNEL-positive cells after $72 \mathrm{~h}$ transfection with Bmi-1 001 siRNA with a statistically significant difference $(\mathrm{P}<0.001)$ compared with that incubated with Lipofectamine 2000 alone or non-specific Bmi-1 siRNA $(\mathrm{P}<0.01)$. Data present the numerical calculated results mean \pm SD of the percentage of TUNEL positive cells.

inhibitor gene p16Ink4a is upregulated (27). Both flow cytometric apoptosis assay and TUNEL assay showed that Bmi-1 specific siRNA treatment resulted in a significant increase in the percentage of cell apoptosis. Downregulation of Bmi-1 expression by means of siRNA transfection could reduce cell viability and lead to apoptosis.

In order to suppress leukemic cell proliferation, inhibiting its source and identifying the gene causing self-renewal of leukemic stem cells would be a new approach. siRNAs have become a promising tool in molecular medicine and a method of molecular therapy for leukemia. Our data revealed that Bmi-1 gene silencing reduces proliferation and leads to apoptosis of U937 cells. These findings suggest that Bmi-1 siRNA silencing might be useful for the treatment of Bmi-1 overexpression in leukemia cells.

\section{Acknowledgements}

We thank Dr Xiaosheng Wu (Mayo Clinic College of Medicine, USA) for reviewing the manuscript. This work was supported by the Natural Science Foundation of the Jiangsu Province (No. BK2008232), Outstanding Medical Academic Leader Program of Jiangsu Province (No. LJ200614), Sci-Tech innovation team and talents of Jiangsu University (grant no. 2008-018-02), and Foundation of the Jiangsu Province for transfer of scientific and technological achievements (grant no. BA2009124), Innovation Project of Jiangsu Graduate Education (No.CX08B-173Z), and the Natural Science Foundation of the Education Ministry of Jiangsu Province (No. 06KJD310040).

\section{References}

1. Haupt Y, Bath ML, Harris AW and Adams JM: Bmi-1 transgene induces lymphomas and collaborates with myc in tumorigenesis. Oncogene 8: 3161-3164, 1993.

2. Van Lohuizen M, Verbeek S, Scheijen B, Wientjens E, van der Gulden $\mathrm{H}$ and Berns A: Identification of cooperating oncogenes in E mu-myc transgenic mice by provirus tagging. Cell 65: 737-752, 1991.

3. Alkema MJ, Wiegant J, Raap AK, Berns A and van Lohuizen M: Characterization and chromosomal localization of the human proto-oncogene BMI-1. Hum Mol Genet 2: 1597-1603, 1993.

4. Jacobs JJ, Kieboom K, Marino S, DePinho RA and van Lohuizen M: The oncogene and polycomb-group gene bmi-1 regulates cell proliferation and senescence through the ink4a locus. Nature 397: 164-168, 1999.

5. Dhawan S, Tschen SI and Bhushan A: Bmi-1 regulates the Ink4a/Arf locus to control pancreatic beta-cell proliferation. Genes Dev 23: 906-911, 2009.

6. Lessard J and Sauvageau G: Bmi-1 determines the proliferative capacity of normal and leukaemic stem cells. Nature 423: 255-260, 2003.

7. Valk-Lingbeek ME, Bruggeman SW and Van Lohuizen M: Stem cells and cancer; the polycomb connection. Cell 118: 409-418, 2004. 
8. Mohty M, Szydlo RM, Yong AS, Apperley JF, Goldman JM and Melo JV: Association between BMI-1 expression, acute graft-versus-host disease, and outcome following allogeneic stem cell transplantation from HLA-identical siblings in chronic myeloid leukemia. Blood 112: 2163-2166, 2008.

9. Beà S, Tort F, Pinyol M, et al: BMI-1 gene amplification and overexpression in hematological malignancies occur mainly in mantle cell lymphomas. Cancer Res 61: 2409-2412, 2001.

10. Van Galen JC, Muris JJ, Oudejans JJ, et al: Expression of the polycomb-group gene BMI1 is related to an unfavourable prognosis in primary nodal DLBCL. J Clin Pathol 60: 167-172, 2007.

11. Vonlanthen S, Heighway J, Altermatt HJ, et al: The bmi-1 oncoprotein is differentially expressed in non-small cell lung cancer and correlates with INK4A-ARF locus expression. Br J Cancer 84: 1372-1376, 2001.

12. Neo SY, Leow CK, Vega VB, et al: Identification of discriminators of hepatoma by gene expression profiling using a minimal dataset approach. Hepatology 39: 944-953, 2004.

13. Kim JH, Yoon SY, Jeong SH, et al: Overexpression of Bmi-1 oncoprotein correlates with axillary lymph node metastases in invasive ductal breast cancer. Breast 13: 383-388, 2004.

14. Qin ZK, Yang JA, Ye YL, et al: Expression of Bmi-1 is a prognostic marker in bladder cancer. BMC Cancer 19: 9-16, 2009.

15. Berezovska OP, Glinskii AB, Yang Z, Li XM, Hoffman RM and Glinsky GV: Essential role for activation of the Polycomb group $(\mathrm{PcG})$ protein chromatin silencing pathway in metastatic prostate cancer. Cell Cycle 5: 1886-1901, 2006.

16. Douglas D, Hsu JH, Hung L, et al: BMI-1 promotes Ewing sarcoma tumorigenicity independent of CDKN2A repression. Cancer Res 68: 6507-6715, 2008.

17. Godlewski J, Nowicki MO, Bronisz A, et al: Targeting of the Bmi-1 oncogene/stem cell renewal factor by microRNA-128 inhibits glioma proliferation and self-renewal. Cancer Res 68: 9125-9130, 2008.
18. Yang J, Chai L, Liu F, et al: Bmi-1 is a target gene for SALL4 in hematopoietic and leukemic cells. Proc Natl Acad Sci USA 104: 10494-10499, 2007.

19. Häyry V, Tynninen O, Haapasalo HK, et al: Stem cell protein BMI-1 is an independent marker for poor prognosis in oligodendroglial tumours. Neuropathol Appl Neurobiol 34: 555-563, 2008.

20. Mihara K, Chowdhury M, Nakaju N, et al: Bmi-1 is useful as a novel molecular marker for predicting progression of myelodysplastic syndrome and patient prognosis. Blood 107: 305-308, 2006.

21. Silva J, García V, García JM, et al: Circulating Bmi-1 mRNA as a possible prognostic factor for advanced breast cancer patients. Breast Cancer Res 9: R55, 2007.

22. Mihara K, Takihara Y and Kimura A: Genetic and epigenetic alterations in myelodysplastic syndrome. Cytogenet Genome Res 118: 297-303, 2007

23. Bhattacharyya J, Mihara K, Yasunaga S, et al: BMI-1 expression is enhanced through transcriptional and posttranscriptional regulation during the progression of chronic myeloid leukemia. Ann Hematol 88: 333-340, 2009.

24. Park IK, Qian D, Kiel M, et al: Bmi-1 is required for maintenance of adult self-renewing haematopoietic stem cells. Nature 423: 302-305, 2003.

25. Itahana K, Zou Y, Itahana Y, et al: Control of the replicative life span of human fibroblasts by p16 and the polycomb protein Bmi-1. Mol Cell Biol 23: 389-401, 2003.

26. Bai J, Zhu X, Zheng $\mathrm{X}$ and $\mathrm{Wu} \mathrm{Y}$ : Retroviral vector containing human p16 gene and its inhibitory effect on Bcap237 breast cancer cells. Chin Med J 114: 497-501, 2001.

27. Molofsky AV, Pardal R, Iwashita T, Park IK, Clarke MF and Morrison SJ: Bmi-1 dependence distinguishes neural stem cell self-renewal from progenitor proliferation. Nature 425: 962-967, 2003. 